Cómo citar este artículo en MLA: Marín Posada, Mary Luz. "Repugnancia y vergüenza: narrativas del mal en excombatientes de FARC en Colombia”. Escritos 28. 60 (2020): 109-124. doi: http://dx.doi.org/10.18566/escr.v28n60.a10

Fecha de recepción: 13.05 .2020

Fecha de aceptación: 11.06.2020

\title{
Repugnancia y vergüenza: narrativas del mal en excombatientes de FARC en Colombia ${ }^{1}$
}

\author{
Disgust and Shame: Narratives of Evil by former FARC Members in Colombia
}

\author{
Mary Luz Marín Posada ${ }^{2}$
}

\begin{abstract}
RESUMEN
Este artículo profundiza en la comprensión del conflicto armado colombiano a partir de emociones políticas de repugnancia y vergüenza. Asimismo, emociones emergentes como amor y miedo en narrativas de dos excombatientes de las FARC, quienes ingresaron a la guerrilla en su infancia y pasaron gran parte de su vida en la lucha armada. En este sentido, esas emociones políticas se vincularon con las dinámicas del conflicto y con las propias vivencias de los excombatientes. Por tanto, fue necesario centrar el análisis interpretativo en la comprensión de creencias, juicios y valoraciones asociados con la libertad y con la voluntad en relación con la dignidad humana. El rastreo de antecedentes se hizo con estudios emblemáticos sobre la violencia en Colombia, en el que se ha dejado de lado la narrativa emocional. La perspectiva teórica que se asume de las emociones políticas es la propuesta por Nussbaum. El análisis narrativo como metodología posibilitó leer rostros de sujetos que han sido socialmente descalificados y estigmatizados; reconocimiento fundamental para la reconciliación. Las emociones activan y desactivan los hechos bélicos: así, la vergüenza activa la búsqueda de verdad, justicia y reparación, la repugnancia potencia la lucha ante la injusticia social, el miedo es una emoción que activa la desconfianza tanto en la guerra como en la paz y el amor implica, para muchos, perder su vida por los otros y recuperar su propia dignidad mediante la entrega a la humanidad para desactivar la acción del daño causado a otro, elementos clave de paz.
\end{abstract}

1 Este artículo de investigación científica y tecnológica, realizado como narrativas, del área de Ciencias Sociales, es producto de "Repugnancia y vergüenza: narrativas del mal en trayectorias de vida de jóvenes excombatientes de FARC en el conflicto armado colombiano". Tesis desarrollada por la autora de este artículo, para optar al título de Doctora en Ciencias Sociales, niñez y juventud. Universidad de Manizales - Cinde. Investigación efectuada entre el 1 de septiembre de 2013 y el 28 de febrero de 2019.

2 Doctora en Ciencias Sociales, niñez y juventud, Universidad de Manizales, Cinde, Colombia. Docente en la Universidad de Antioquia, Colombia Correo electrónico: maryl.marin@udea.edu.co. 
Palabras clave: Conflicto armado; Emociones políticas; Dignidad humana; Voluntad; Libertad.

\begin{abstract}
The article contributes to a deeper understanding of the Colombian armed conflict by considering it from the perspective of the political emotions of disgust and shame. It also considers emergent emotions such as love and fear in the narrative of two former members of FARC, who were part of the group since their childhood and spent most of their lives in the armed conflict. Thus, these political emotions are linked to the dynamics of the conflict and to the experiences of the former members. The interpretative analysis focuses on understanding the beliefs, judgments and assessments associated with liberty, will and human dignity. The literature review included major works regarding violence in Colombia and it revealed that such works did not considered emotional narrative. The conceptual framework is built around Nussbaum's political emotions and the methodology is that of narrative analysis, which made possible to read the faces of individuals that have been disqualified and stigmatized, an acknowledgement that is necessary for reconciliation. Emotions activate and deactivate war actions: shame activates the search for truth, justice and reparation; disgust activates the fight against social injustice; fear activates distrust during war and peacetime; and love activates the possibility for many to sacrifice their lives and to recover their own dignity through devoting themselves to humanity and to deactivate the action of harm caused to others.
\end{abstract}

Keywords: Armed Conflict; Political Emotions; Human Dignity; Will; Liberty.

\title{
Introducción
}

$\mathrm{E}$ ste artículo, derivado de la investigación Repugnancia y vergüenza: narrativas del mal en trayectorias de vida de jóvenes excombatientes de FARC en el conflicto armado colombiano, ahonda sobre emociones políticas en el conflicto armado en Colombia. Las emociones políticas acompañan los hechos bélicos, están ancladas a creencias, son evaluativas, permean los juicios, se aprenden, se comunican y se construyen en la vida con otros:

Las emociones no encarnan simplemente formas de percibir un objeto, sino creencias, a menudo muy complejas, acerca del mismo (...) para sentir ira debo poseer un conjunto de creencias aún más complejo: que se ha infligido un perjuicio, a mí o a algo o alguien cercano a mí; que no se trata de un daño trivial, sino relevante; que fue realizado por alguien; probablemente que fue un acto voluntario. (Nussbaum, 2008, p. 51)

Subyacen de distintos modos a los relatos de la violencia en Colombia, por lo que se hace necesario reconocer y visibilizar su rol en la activación o inhibición de los hechos bélicos.

Entre los modos de leer el conflicto armado colombiano, identificados en informes y estudios investigativos, resaltan los que han puesto su mirada en la actuación moral de los victimarios, en el perfil moral de los actores, cuando es posible hacerlo: "Alias Chispas, analfabeta total de la vieja guardia liberal, quijote de su idea, un romántico de la política, lo que más lo hizo sufrir fue ver a la mamá llorando de hambre en el monte, mientras ardía la casa” (Guzmán et al., 2014 p. 207).

En la valoración jurídico-política de sus acciones, en el drama humano de las víctimas y en los medios que los grupos armados utilizan para lograr sus propósitos, tipificando las acciones como delito, así como las afectaciones en términos de dignidad humana (Kant, 2007) (delitos de lesa humanidad): 
Los paramilitares ejecutaron en mayor medida masacres, asesinatos selectivos y desapariciones forzadas, e hicieron de la sevicia una práctica recurrente con el objeto de incrementar su potencial de intimidación. Las guerrillas, por su parte, han recurrido primordialmente a los secuestros, los asesinatos selectivos, los atentados terroristas, además del reclutamiento forzado y el ataque a bienes civiles. (Centro Nacional de Memoria Histórica, 2013, p.20).

Las emociones se tipifican desde lo jurídico como agravantes o atenuantes que dicha acción contenga, por tanto, son también móviles o motivos emocionales. Así, la repugnancia y la vergüenza, entre otras emociones, quedan circunscritas a sus implicaciones legales (Nussbaum, 2012). Sumado a esto, los informes sobre la violencia en Colombia buscan mostrar el drama humano presente en el conflicto, narrando, a partir de experiencias personales y familiares, en particular, el drama de las víctimas:

Yo le dije a mi hijo que él no tenía necesidad de andar metido en grupos armados, que él ya era un desmovilizado con ayuda del gobierno, pero él no me hizo caso y yo no fui más enérgica para impedirle que se fuera. Si yo me hubiera hecho sentir tal vez él estuviera hoy conmigo (Centro Nacional de Memoria Histórica, 2013, p. 265).

En estos relatos centrados en el drama humano se develan emociones políticas (Nussbaum, 2014), aunque los autores no las nombren de esta manera, ni profundicen en la comprensión del lugar de dichas emociones en los móviles de la acción. Finalmente, las investigaciones acerca de los niños, niñas y jóvenes miembros de grupos armados, y algunos estudios investigativos, ponen la mirada sobre el modo cómo estos fueron entrenados como victimarios y por qué son leídos por los investigadores como víctimas:

Los más graves crímenes se causan durante las primeras etapas de la vinculación. En el marco del entrenamiento, los niños y las niñas son sometidos a un complejo proceso de deshumanización en el que se les prepara para asesinar con indiferencia, violentar sin límite y sin pudor. Los reclutan, los retienen y los obligan a convertirse en victimarios. (Springer, 2012, p. 9).

Desde esta mirada, las emociones de niños y jóvenes no son interpretadas como propias sino como inducidas, lo que podría develar móviles emocionales originarios que es necesario visibilizar para comprender la experiencia humana y política que subyace a sus acciones.

Este ejercicio de investigación se desarrolló desde que se iniciaron los diálogos de paz con las FARC (Revista Semana. Mayo 12 de 2020), por lo tanto, su elaboración coincidió también con los momentos de incertidumbre que conllevó el proceso de negociación, como el plebiscito nacional por la paz (El Tiempo. Octubre 2 de 2016), la firma en medio de la inestabilidad que generó la polarización del país, los incumplimientos por parte del Gobierno frente al acuerdo firmado, el desconcierto ante el asesinato de líderes y excombatientes en Colombia, la suspensión de diálogos con el ELN (El Espectador. Enero 18 de 2019), el incremento de las disidencias y desertores de las FARC, la reorganización de estructuras del crimen organizado y el recrudecimiento de la violencia en el país (Estrada, 2019).

En este sentido, las narrativas configuradas develaron el lugar que ocupan las emociones en lo bélico, que afectan la vida con otros, es decir, la vida política. Por eso se habla de emociones políticas. Para ello, se contó con las voces de excombatientes que ingresaron a las FARC desde su infancia y permanecieron toda su juventud, incluso la adultez, en dicha organización, hasta la firma de los acuerdos de paz en 
2016: "Yo paso de ser ese niño campesino a joven militar, y ahora de joven militar a campesino" (E11, M, 40;830-831).

En un país tan polarizado como el nuestro, es fundamental comprender el lugar que ocupan emociones como la vergüenza y la repugnancia; también el miedo y el amor, en la construcción y la lucha por la verdad, la justicia y la reparación, clave en la conquista de la paz.

\section{Metodología}

Las emociones han sido observadas desde distintos lentes y esas lecturas dependen de dónde se sitúe el lector: "reinterpretar la identidad narrativa que nos constituye a la luz de los relatos que nos propone nuestra cultura" (Ricoeur, 2006, p. 9). Es decir, los humanos se comunican contando. Cuando se habla de una acción se habla del significado de ese movimiento. El sujeto en la mirada hermenéutica está siendo para llegar a ser, así la narrativa se constituye en un acto de configuración y de reconfiguración de sí con otros: "Nace un sí mismo instruido por los símbolos culturales, en cuya primera fila están los relatos recibidos de la tradición literaria. Son ellos quienes nos confieren una unidad no sustancial sino narrativa" (Ricoeur, 2006, p. 10). Por tanto, la identidad narrativa que se construye con las historias que se cuentan no tiene características de esencia sino de creación, que se produce a partir de las tradiciones. Esto significa que toda narración se teje en la relación entre "tradición" e "innovación", de manera dinámica y nunca definitiva. Por ello, las historias contadas por los jóvenes excombatientes tienen rasgos de los discursos de la organización a la que pertenecieron, a la vez que toman distancia de ella, y en este movimiento resignifican su identidad.

Al respecto, el investigador es también un conversador movido por emociones que permean su experiencia, las cuales afloran en los momentos de acercamiento e interpretación de los relatos, leídos también desde una tradición, pero intentando crear una nueva mirada sobre su objeto (en este caso, el conflicto armado colombiano, narrado emocionalmente).

Las categorías y subcategorías de análisis fueron los conceptos fundamentales que definieron el corpus teórico y la lectura de los antecedentes investigativos, y también son la clave de interpretación de las narrativas. Las categorías son: emociones políticas como la repugnancia y la vergüenza, y las subcategorías son los rasgos de dichas emociones: creencias, juicios y valoraciones (evaluaciones). Asimismo, funge como categoría el mal (Arendt, 1974) en el conflicto armado, y como subcategorías la dignidad humana (Kant, 2007) y la libertad (Safranski, 2000).

\section{Sujetos de la narrativa}

Para esta investigación se realizaron 12 entrevistas en profundidad a hombres y mujeres excombatientes de las FARC (El Tiempo. 2016), seleccionados por pertenecer largo tiempo a la guerrilla; haber ingresado desde la infancia; tener liderazgo en la organización y haber desempeñado varios roles en esta. Posteriormente, se seleccionaron dos entrevistas, la primera narrativa corresponde a un hombre llamado 
Tabla 1. Categorías y subcategorías de análisis e indicadores

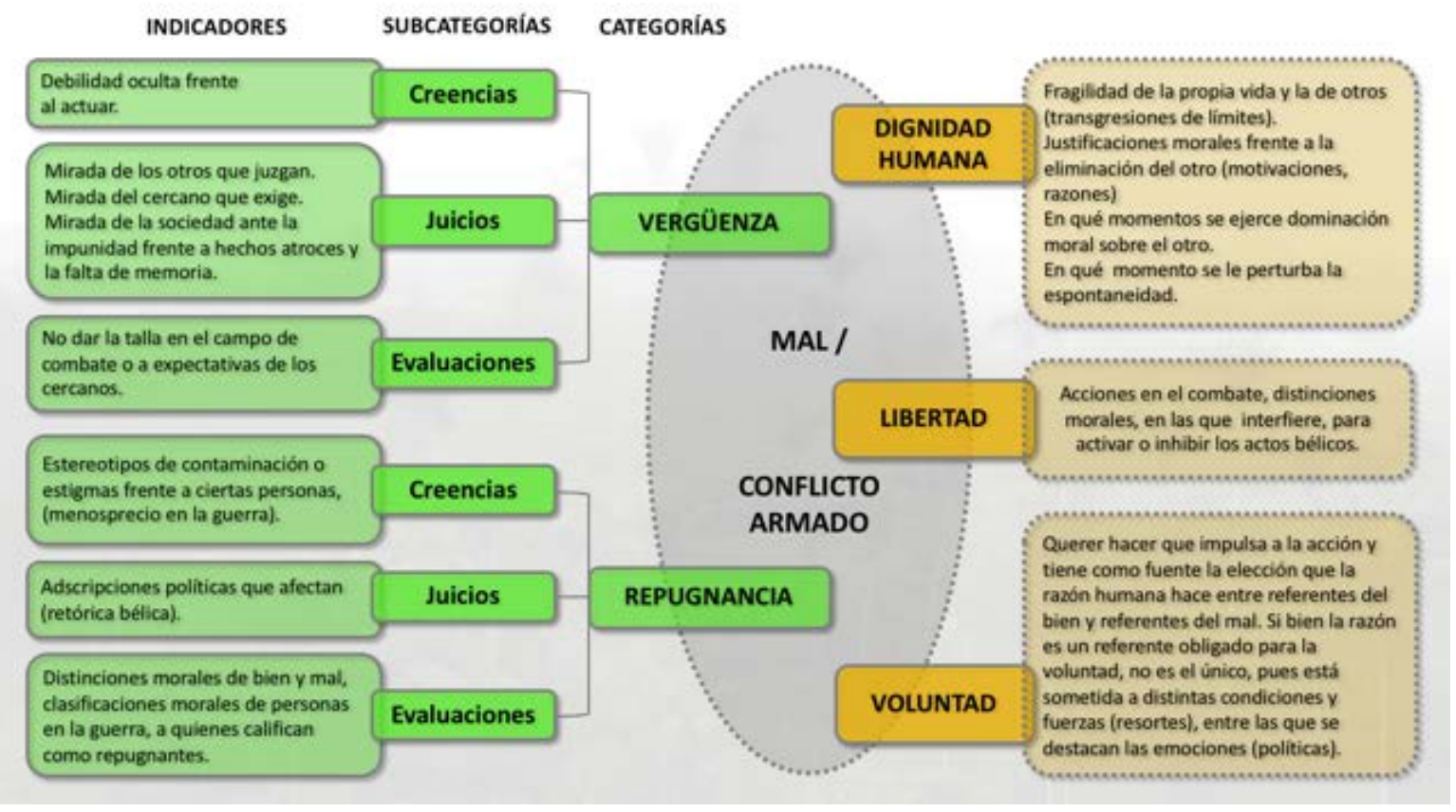

Robert $^{3}$, que ingresó a las FARC a sus 10 años y estuvo 30 años en la organización. La segunda narrativa es de Mónica, una mujer que ingresó a las FARC a los 14 años y estuvo 25 años vinculada a ella.

\section{Diseño de la investigación}

La información se procesó con el método de Análisis de Narrativas, diseñado y validado por la investigadora Marieta Quintero (Quintero, 2018)4. Esta propuesta va en la vía de reconocer dimensiones fundamentales como el lenguaje, la experiencia humana, la reflexividad y la imaginación narrativa (Nussbaum, 2014). La estrategia de análisis e interpretación se desarrolló a través de momentos de la construcción narrativa de la siguiente manera.

Momento 1: Registro de codificación

Momento 2: Nivel textual. Preconcepción de la trama narrativa

Momento 3: Nivel contextual de la trama narrativa

Momento 4: Nivel metatextual. Reconfiguración de la trama narrativa

3 Los nombres de los sujetos de las narrativas fueron acordados con ellos y ratificados en el momento de devolución de la narrativa.

4 Esta metodología cuenta con validación, ya que ha tenido otros desarrollos por parte de la autora y algunos de sus estudiantes. Se ha aplicado desde el año 2006. 
Para el momento 1 (registro de codificación), se requirió haber recogido previamente la información mediante la aplicación de técnicas de narración (el relato, entrevistas narrativas -en profundidad-, historias de vida, narrativas biográficas, entre técnicas de este tipo), la cual se codifica en su totalidad con el propósito de resaltar la voz del narrador de modo literal (Quintero, 2014, pp, 147-148).

El segundo momento (nivel textual. Preconcepción de la trama narrativa) se dio un acercamiento descriptivo a acciones y experiencias, teniendo como referentes los hechos, las temporalidades y las especialidades. "Implica la aproximación al sentido y al significado que el sujeto de la narración les otorga a sus experiencias vividas, estructuradas en forma de narrativa. (...) A partir del tema, y/u objetivos del estudio se seleccionan los enunciados relacionados con acontecimientos y/o experiencias" (Quintero, 2014, pp. 147-148). Así, en la acción se puede ver una estructura y cuáles son los significados de esa acción para el sujeto que narra. Se puede leer desde interrogantes como: ¿Qué pasó? ¿Cómo pasó? ¿Dónde pasó? ¿Cuándo pasó? ¿Por qué pasó? Esto proporcionó construir un primer texto descriptivo de los hechos siguiendo las voces de los actores e identificando las distintas temporalidades de la narración.

En el tercer momento (nivel contextual de la trama narrativa), se clasificaron los acontecimientos y expresiones de los actores según la fuerza narrativa. Esto permitió hacer visibles las expresiones y actos de habla de los actores, además, mostrar rasgos de subjetividad, sus juicios morales, sus posturas políticas, sus valoraciones, imputaciones o responsabilidades, potencialidades, capacidades (Quintero, 2014, pp. 160-163), y ahí, como interés de esta investigación, sus emociones políticas. En el cuarto momento (nivel meta-textual. Reconfiguración de la trama narrativa).

El metatexto consiste en una nueva lectura de la trama narrativa resultado de: a) La interpretación en cada uno de los dos anteriores momentos. b) El diálogo con otras voces que pueden provenir de otros actores, sujetos o textos de la enunciación, como horizontes de referencia teórica. (Quintero, 2014, p.164).

Se consolidó aquí la narrativa del investigador, quien, dando paso a las polifonías, otros textos, sus preguntas, sus categorías, hizo visible el lugar de las emociones políticas en narrativas de jóvenes excombatientes del conflicto armado colombiano.

En este procedimiento de reconfiguración se elevan y se potencian las significaciones del relato narrado, se amplifica la obra del narrador, incluso episodios que parecían desapercibidos, pues con la devolución a los narradores de sus narrativas, estos sintieron implicación en la obra de su vida transformada e intervenida por el investigador. Sintieron que nos conocíamos desde adentro y ese conocimiento nos convirtió en cómplices de la vida, así nuestras cotidianidades fuesen distintas. Imaginar sus infancias en el campo, su juventud en la guerrilla, tan distinta a la mía en la ciudad, en la casa, en la escuela, permitió que nos identificáramos con rostros humanos y cercanos. En este sentido, este acercamiento desde lo vital otorgó que brotara esta obra desde lo íntimo para finalizar en una reconfiguración con la devolución de los relatos. Es ahí cuando termina la construcción de la narrativa y se abre a otros lectores que, como ellos y como yo, aportarán nuevos elementos desde sus horizontes de sentido a la interpretación de la narrativa.

La interpretación es el proceso por el cual la revelación de nuevos modos de ser, o de nuevas formas de vida, da al sujeto una nueva capacidad para conocerse a sí mismo (...) el lector crece en su capacidad de auto proyección al recibir del texto mismo un nuevo modo de ser. (Ricoeur, 2006, p. 106). 
Nosotros no seremos más los mismos, pues estamos implicados en una obra conjunta que primero se narró desde ellos y luego se construyó desde la investigación con nuevas preguntas, lo cual produjo una fusión de horizontes (Gadamer, 1977) que se materializó en la narrativa y que regresó al narrador como primer lector. De esta manera se creó y se crea un vínculo entre narrador, investigadora y lector.

\section{Resultados}

\section{Narrar la repugnancia}

El conflicto armado se justificó por sus actores y, sobre todo, por los que lo han organizado y pensado, quienes pusieron por delante un fin justo. Por eso, se concluye, desde las narrativas de los excombatientes, que es impensable una guerra que se inicie afirmando que por sí misma es injusta. En el caso de las FARC, el móvil para justificar su accionar bélico fue el argumento de crear un poder necesario para defender un pueblo de los ataques de otros, principalmente del Estado. En palabras de Manuel Marulanda:

Ya no solo los estaremos esperando en la otra orilla del río, ya no solo los estaremos esperando en la otra región. Ahora volveremos a buscarlos en la orilla del río de donde un día nos sacaron, volveremos a buscarlos en la montaña, de la cual un día nos hicieron salir a la huyenda, volveremos a buscarlos en la región de la que un día nos hicieron correr. (Resistencia, 2009, p. 12).

Es en este sentido que el conflicto armado se autojustifica, pues los actores consideran que lo hacen desde una mirada salvadora, pensando que la sociedad se va a transformar y que las injusticias desaparecerán de alguna manera: "Yo tomé esa decisión por tanta crueldad que yo veía (...) Esto no es justicia, yo me voy para la guerrilla" (E11, M,40; 61-65).

Para muchos la crueldad de la guerra no estaba prevista, se pensaba que una acción bélica sería el detonante para frenar la inequidad, las injusticias y así terminar con la guerra: "La guerra es un acto de fuerza y no hay límite para su aplicación. Los adversarios se justifican uno al otro y esto redunda en acciones recíprocas llevadas por principio a su extremo" (Clausewitz, 2002, p. 55).

Desde los narradores, el móvil que los empujó a la guerra no fue la crueldad sino la justicia (Rawls, 1997). Sin embargo, el poder del opositor y el argumento de que era necesario hacer una eliminación completa del enemigo, los llevaría a incursionar en acciones bélicas que necesariamente produjeron destrucción humana: "Yo estoy acá luchando por el pueblo, pero estoy matando ese pueblo, entonces qué estoy haciendo" (E11, M, 40; 179-180).

Los bombardeos también les generan repugnancia (Marín, 2018), en tanto se hacían en lugares en los que los actores de la guerra iban a ser afectados de manera desmedida y las propias fuerzas militares estatales, pero no importaba quién estuviera allí: "Mandar una bomba de mil y más kilos" (E11, M, 40; 15). Los bombardeos siempre desbordan hacia la crueldad, hacia el horror. Igualmente les causa repugnancia el tipo de tecnología y de sustancias mortíferas utilizadas para envenenar el medio ambiente, o el uso de armas de largo alcance que en el derecho de guerra están prohibidas, lo cual consintió el abuso de todas las formas de muerte: "Contaminando el aire se está exterminando no solo al ser humano: para mí esa sí 
es una crueldad” (E11, M, 40; 15-20); “los encontré como si fuera un costal, o sea, sin huesos. Para mí eso es muy doloroso" (E11, M, 40; 575-579).

En el derecho de guerra muchas de estas acciones están prohibidas, lo cual ha asentido el abuso de todas las formas de muerte:

El derecho internacional humanitario forma parte del cuerpo de derecho internacional que rige las relaciones entre los Estados. El DIH tiene por objeto limitar los efectos de los conflictos armados por razones humanitarias. Su finalidad es proteger a las personas que no participan o han dejado de participar en las hostilidades, a los enfermos y heridos y a los prisioneros y las personas civiles, y definir los derechos y las obligaciones de las partes en un conflicto en relación con la conducción de las hostilidades. (CICR, 2010).

Estos tratados han definido la guerra y calculado su alcance de la manera menos cruel posible, sin embargo, sustancias usadas de manera indiscriminada hacia la población y el medio ambiente, expresan pura crueldad y repugnancia.

La inutilidad de la guerra se les hizo evidente cuando ya deja de ser la salida para defenderse ante las injusticias. La guerra terminó siendo moralmente repudiable, teniendo en cuenta que se estaba siendo agente de crueldad. Esta responsabilidad hace que se actúe desde la responsabilidad frente al sufrimiento causado, lo que implica llegar al juicio respecto a que la guerra es inútil: "Para mí, en realidad, pues, queda uno como con un repudio, como que no quisiera que se repitiera eso, porque de verdad que no es, no es humano; es inhumano" (E11, M, 40; 37-40).

\section{Narrar la vergüenza}

La vergüenza en la guerra (Marín y Quintero, 2017) se asume en distintos sentidos: la vergüenza suscitada por las injusticias presenciadas o vividas, que hace sentir al sujeto inferior a la responsabilidad de defender a su comunidad o a su familia; y la vergüenza que se siente al no mostrar la suficiente valentía para ser reconocido como un guerrero. De la misma manera, cumplir la palabra le otorgaba al excombatiente dignidad y respeto, porque honraba sus compromisos: "Vamos a echar para adelante, para atrás sería yo ser cobarde, para atrás sería no cumplir con mi palabra" (E11, M,40; 190-191). En este sentido, para estos excombatientes el incumplimiento de la palabra, de los compromisos, es motivo de gran vergüenza. Mientras que ser consecuente y cumplidor de la palabra es motivo de honra, pues da valor pleno a la acción que se realiza. La palabra dada es un hiperbien (Taylor, 1996), hace ética la acción. Se da la vida por la palabra dada. Por esta razón, no es aceptable volver atrás.

Estos excombatientes llegaron a sentir orgullo de ser guerreros, ya que la vida que llevaban antes de ingresar a las FARC, de alguna manera, les producía vergüenza en el sentido que no podían ser niños con posibilidades y garantías para una vida buena (Aristóteles, 1993). Uno de los narradores, por ejemplo, sentía que no podía quedarse quieto en medio de los avatares y las injusticias que se vivían en su pueblo. Por eso este excombatiente siente vergüenza al ser parte de una nación que no ha respondido ante la negación de la dignidad humana, ante las víctimas que reclaman justicia y verdad: "Hubo asesinatos a líderes que en realidad no tenían nada que ver con lo que era el conflicto armado en Colombia" (E11, $\mathrm{M}, 40 ; 2-3)$. 
De este modo, el juicio que la vergüenza produce lleva a dicho excombatiente a hacerse solidario con las víctimas. En principio, la vergüenza se activó antela impotencia moral que se siente al verse desprotegido por el Estado. Luego la vergüenza se profundiza cuando siente que muchos otros también están desprotegidos como él. En este sentido, se activa la solidaridad con los que viven injusticia y, al hacerlo, emerge el orgullo de ser capaz de defender a su pueblo y su familia, justificando así su accionar en la guerra:

La vergüenza (...) que siente el justo ante la culpa cometida por otro, que le pesa por su misma existencia, porque ha sido introducida irrevocablemente en el mundo de las cosas que existen y porque su buena voluntad ha sido nula o insuficiente y no ha sido capaz de contrarrestarla. (Levi, 2015, p. 531).

Para una de las narradoras, la vergüenza aparece ante una vida que valora como plana, sin sentido y sin futuro; sentía en el fondo que podía ampliar su horizonte de vida ingresando a las FARC. Así, ambos empezaron a sentir orgullo, sobre todo por ser admirados y temidos; orgullo de ser defensores del pueblo en el campo colombiano. Sin embargo, esa defensa culminó en vergüenza, teniendo en cuenta que muchos campesinos terminaron siendo trinchera y víctimas de las disputas y enfrentamientos entre los distintos actores de la guerra, entre ellos las FARC. Esa vida dedicada a defender el pueblo terminaba también siendo parte del exterminio del mismo pueblo, y eso era vergonzante para ellos y los cuestionaba todo el tiempo: "A uno le da mucho pesar en Bojayá, la muerte de los diputados también y muchas otras, la del gobernador" (E3, M, 35; 257-268).

Es aquí cuando la vergüenza actúa como señal de alerta frente al respeto de la dignidad humana, pues la crueldad humana se desborda y origina en estos excombatientes una necesidad de parar la guerra. Estos excombatientes sienten la vergüenza de una manera personal, culpabilizándose y responsabilizándose. Así los errores los hubiesen cometido sus camaradas, ellos los sienten de manera propia, ya que les parece inaudito que sucedan estas cosas. La vergüenza les exige, en consecuencia, con su juicio moral, pedir perdón a las víctimas por sus acciones o por las de sus compañeros.

Los extremos a los que confina una guerra reflejan la pérdida de espontaneidad, la poca libertad para vivir y decidir lo que se quiere en realidad. El móvil inicial para ir a la guerra fue defender la familia de todos los atropellos a los que estaba sometida, pero ellos sienten que no cumplieron con la promesa hecha a ellos mismos, que la iban a proteger, que no iban a dejar que pasara nada. Porque esta promesa, paradójicamente, originó más peligro a sus familias, hizo que sus parientes fuesen más vulnerables al daño del bando contrario. Y esto los avergüenza porque ellos y sus familias terminan silenciados por temor, lo cual coarta la libertad: "Mi familia se tuvo que cambiar el apellido por la persecución de mi apellido" (E11, M, 40; 421-427). Este rasgo de vergüenza hacia sus familias es bastante frecuente en ellos, pues casi todos coinciden en haber expuesto a sus familias a la zozobra, a la angustia que representa tener que estar escondido, cambiar de domicilio una y otra vez y, en el peor de los casos, estar expuestos a la desaparición y el asesinato:

La vergüenza alcanza su configuración específica en el hecho de que quien la padece está haciendo o piensa hacer algo que lo obliga a incurrir en contradicción con las personas a las que se encuentra unido de una u otra forma. (Elías, 2012, p. 594).

La familia, siendo un vínculo sagrado, termina afectada y esto les suscita culpa, sentimientos de abandono, lo que los lleva también a sensibilizarse moralmente, así que la vergüenza opera como catalizadora del mal producido y transformadora del juicio moral construido en la guerra. 
La vergüenza también tiene que ver con la creencia de estos excombatientes de que el pueblo colombiano era sensato, que entendía lo que había pasado con la guerra y que era el momento de construir la paz; pueblo por el que se había luchado, al que se le había enseñado a tener una conciencia política. Esa fue siempre su labor educativa y pedagógica, por lo que se esperaba que el pueblo actuara en defensa de la justicia. Para ellos era obvio que el pueblo quisiera una sociedad justa y en paz, pero se avergonzaron al darse cuenta que no todo el pueblo colombiano reconoció este proceso de paz, y a ellos como sus artífices: "siento vergüenza por Colombia (...) la gente decir que, por ejemplo, cuando el plebiscito, decir que quieren la guerra" (E3, M, 35; 285-295).

Esto para ellos significó vergüenza de este pueblo colombiano, al que se había idealizado, y que supuestamente había cambiado su conciencia a causa de su lucha. Queda para ellos en evidencia que el trabajo realizado en comunidades se diluyó: "en una sociedad todos somos responsables de su presente y que la guerra habita sobre todo en el alma" (Castillejo, 2013, p.349). No obstante, la vergüenza también potencia la esperanza en la justicia y abre la posibilidad de vivir otro horizonte de sentido moral del bien. La vergüenza hace que se activen las fuerzas sensibles para exculpar los hechos atroces cometidos por la organización armada, es la posibilidad de hacer un juicio reflexivo sobre lo ocurrido para resignificar el sentido de la paz y abrir una ventana al bien y, por tanto, la verdad emerge como un móvil fundamental para dicha resignificación. No decir la verdad ha significado esconder la crueldad y evadir la responsabilidad por las acciones inhumanas de todos los actores, ellos incluidos: "O sea, la verdad, mejor dicho, es la reparación, es la madre de todo" (E11, M, 40; 510).

La mentira y el silencio implican, para ellos, que sus móviles para la guerra no sean reconocidos y que, por tanto, la reconciliación no sea posible. Igualmente sienten que, al no decir la verdad, las víctimas, quienes son parte del pueblo por el que lucharon, no van a ser reparadas y sus responsables no asumirán lo que les corresponde en esta guerra.

Asumir su responsabilidad en la guerra posibilita una disposición a ser juzgados, a decir la verdad, a pedir perdón y a reparar los daños y, de esta manera, lograr recuperar su dignidad humillada por violencias y exclusiones para volver a sentirse dignos. Al hacerse responsables se recupera también la libertad, sin la cual la dignidad humana no se restablece. Se deja de estar gobernado por la guerra para destinar su vida ahora a construir la paz a costos que para ellos son impredecibles. La decisión es clara: no volver a ser guerreros.

Yo firmé un acta que decía: no más armas en mis manos. Yo di mi palabra, yo soy hombre y de palabra. Me han hecho varias entrevistas en las que me preguntan ¿usted vuelve a la guerra? Pienso que tenemos entre todos que cumplir lo que hemos pactado (E11, M, 40; 806-809).

Es vital entender que la guerra y la paz están motivadas por la dignidad humana para estos dos excombatientes, pues en lo concerniente a la guerra, la dignidad humana es una motivación que estuvo presente durante la negociación de paz y por ella vale la pena tener esperanza. La paz merece todo el cuidado y la fuerza de la vida con y por la comunidad. Para los excombatientes, la guerra no es un modo de vida deseable, no quieren que sus hijos la continúen, tampoco el país. Por eso les indigna saber que muchos actores en Colombia, y en el mismo pueblo, siguen creyendo en ella como una alternativa posible para un futuro mejor y justo.

La vergüenza potencia también hechos de resistencia y se convierte en un móvil muy importante para la memoria y en especial para el uso de la memoria ejemplar: "El uso ejemplar de la memoria permite 
utilizar el pasado con vistas al presente, aprovechar las lecciones de las injusticias sufridas para luchar contra las que se producen hoy día, y separarse del yo para ir hacia el otro" (Todorov, 2000, p.13).

Es así como la vergüenza puede ser ejemplarizante, ya que como juicio motiva a realizar actos de reparación, como pedir perdón a las víctimas y al país. Posibilita también reflexionar y elaborar lo sucedido en la guerra, al tiempo que puede causar disposición hacia desafíos como la construcción de paz en Colombia: "Yo se lo aseguro que hay mucha gente reflexionando, ¿por qué se lo digo?, porque mucha gente en estos últimos días hemos comenzado a vivir esta nueva vida" (E11, M, 40;352-354).

\section{Narrar el amor}

El amor se ha hecho visible en medio de las vicisitudes que representa el momento de posacuerdo, a pesar de todas las limitaciones e incumplimientos que se han presentado con los acuerdos de paz firmados en La Habana. No obstante, es también posible reconocer el amor en los móviles que los llevaron a dejar la guerra y a empeñarse ahora en construir la paz. El amor en la guerra emerge como una respuesta emocional que aspira a desactivar la acción del daño causado a otro. Es decir, se intentan cortar los hechos de horror con el amor, que los lleva a insistir o a buscar tener un futuro por fuera de la guerra, de modo que la comunidad Fariana se fortalezca y que el pueblo tenga otras condiciones de vida.

Esta emoción se convierte en una causa, que para ellos en el fondo sería la misma causa o fin que los motivó a entrar a las FARC; pero ya por otros medios, sin armas:

El amor es ese movimiento intencional gracias al cual, partiendo del valor dado de un objeto, se visualiza su valor más alto. De esta manera el valor no es simplemente una reacción a un valor ya experimentado, sino una exaltación, un realzamiento del valor, crea. (Ricoeur, 2009, p.25).

Siempre su postura amorosa va a privilegiar el amor al mundo y el amor al pueblo, por encima de los amores particulares, como se hace visible en una de las narradoras, quien restringió el modo de ser madre en la guerra por condiciones desfavorables que no eran aptas para asumir la maternidad en el terreno de combate: "Muy duro, sí, eso es muy difícil, uno saber que yo estoy teniendo a mi hijo, pero que por ahí cuando tenga dos o tres meses, voy a entregarlo" (E3, M, 35;165-167).

Ambos narradores se quedan en las FARC cultivando su amor al mundo, pretendiendo acabar las injusticias para ellos y el pueblo, para garantizar y defender su dignidad, ya que no cuentan con el Estado. En esta lucha también aparece el amor por la humanidad y su dignidad. En el caso de Mónica, y de muchos excombatientes, ella decide arriesgarse y sacrificarse por los otros, dándole mucha más fuerza a lo colectivo. Este amor-sacrificio implica para muchos perder su vida por los otros y recuperar su propia dignidad mediante la entrega a la humanidad. Este compromiso se basta a sí mismo y produce satisfacciones que justifican la vida: "Es que la lucha no es personal, es una lucha que es hasta el final, es vencer o morir, es tomarnos el poder, sea por la vía militar o por la vía política” (E3, M, 35; 165-167).

Ser ético en la guerra fue entendido como respetar el pacto acordado por la organización, según la cual, la crueldad (Uribe, 2009), la sevicia, la violencia sexual, la violencia contra menores o personas indefensas, entre otras, no estaban facultadas. Esto es mantener al máximo un respeto por la dignidad humana aun en el contexto de la guerra. Igualmente, ser ético fue entendido como fidelidad a la organización y a su pueblo. La lealtad, el respeto por la palabra empeñada, el cumplimiento de las promesas, el sacrificarse y dar la vida por la comunidad y su pueblo, se constituyeron en principios que no solo buscaron ser seguidos 
por los excombatientes, sino también reclamados y exigidos firmemente a sus compañeros. Violar estos principios, tanto por otros como por ellos mismos, implicaba asumir un castigo que consideraban merecido. La coherencia con estos principios éticos dentro de la organización (FARC- EP, 1966) les daba a ellos el sentido del valor moral del colectivo al que pertenecían y de la causa por la que luchaban.

En tiempos de paz, la libertad toma otras connotaciones. Por una parte, la vida va a ser conducida por su propia decisión y no por las decisiones de sus superiores. El sujeto sin armas queda en igualdad de condiciones en cuanto a poder, por lo que tiene que conquistarse un lugar en el mundo y en la sociedad por medios distintos que quizá no conoce. La libertad, para ser considerada como tal, requiere de estas condiciones de igualdad. En la organización, gran parte de la vida les fue decidida por el colectivo y sus jefes, constituyendo un cierto modo de vida en el que se les eximía de tomar decisiones sobre este. Esto puede entenderse también como una restricción al ejercicio de las libertades. Hoy, ambos reconocen como muchos otros excombatientes, que estar en libertad en la vida sin armas, sin órdenes, si bien puede concebirse como un tiempo de la esperanza, también, como lo expresa uno de los narradores, es difícil manejar, por ello incorporarse a la vida civil les implica tomar decisiones en un contexto que les es extraño:

Ahora saltamos de esta vida donde nos estaban orientando porque igual entonces hay una colectividad que orienta a esta otra y la persona siempre está esperando que lo manden, "haga tal cosa", "vámonos para tal parte", "vámonos por acá", "hagamos esto", ¿cierto?, siempre la gente está esperando eso y eso es lo difícil en este momento. (E11, M, 40;767-772).

Esta libertad de continuar amando a la organización y al pueblo, después de firmar la paz, deposita todos sus sueños en pensar en tejer comunidad hoy, en medio de la reincorporación a la vida civil, pero con la comunidad como partido y también como organización en la ruralidad con sus proyectos productivos, redes de solidaridad y de sobrevivencia que funden sinergias en el campo: "En este momento lo que siento es libertad" (E11, M, 40; 736).

En su resignificación de la libertad, muchos de estos excombatientes no conciben la paz con armas, por eso han decidido no continuar siquiera con armas dentro de la legalidad (escoltas), lo que les significa volver de otra manera al modo de vida anterior: el hastío de las armas y la decisión de no volver a empuñarlas, los lleva a construir otro modo de subsistencia y de vida. La libertad les significa ahora liberarse de las armas.

La voluntad (Kant, 2007) para estos narradores se refleja en la permanencia en la organización FARC y la obediencia que tuvieron siempre ante sus estatutos, al igual que la disposición y el compromiso con la paz, a pesar de todos los altibajos que ha presentado el posacuerdo. Del mismo modo, en la fuerza y el amor al pueblo campesino, la voluntad aparece como una disposición a la realización plena de aquello en lo que se cree; actúa como principio y movilizador de la acción, se configura como sentido de vida, esto es, aquello por lo cual vale la pena dar la vida. Por ello, se suele nombrar como causa: vivir, o vivir y morir por la causa que para ellos es el pueblo encarnado en su organización.

Hoy, más allá de la obediencia a los estatutos o a los comandantes, su voluntad articulada a emociones políticas toma otro tinte, se configura como una decisión y opción de vida propias, con principios resignificados, lo que los lleva a buscar ser éticos en la paz, así como quisieron serlo en la guerra. La ética desde estos elementos y posturas configuran su voluntad de paz: 
La vida de la paz en lo bonito que se ve de la colectividad en el ETCR ${ }^{5}$ La Plancha, mucha gente desconoce esa parte. Estamos reunidos con la policía, el ejército y la comunidad. Es mi compromiso, nunca me sentí rendido, fuimos a la mesa de diálogo por voluntad propia, porque sentimos que podíamos salvar vidas".

(E11, M, 40; 782-783).

Así mismo, la lealtad es un sentimiento relacionado con el amor entendido como fidelidad a quien se ama, que engloba decisiones tanto para el bien como para el mal, pues es la que habilita seguir esperanzado en la paz y no dar un paso atrás por más complicaciones que se presenten. La lealtad permea el amor y funge como dispositivo a permanecer en el bien, fiel a la causa, a cultivar humanidad (Heller, 2004) y a creer en un mundo mejor para ellos, su comunidad y su pueblo.

En la reconciliación es fundamental que el amor esté presente, y su carácter comunicativo admite la comprensión de los actos que dañaron, exponiendo razones, motivos, reflejando así dimensiones morales del daño ocurrido, propiciando vínculos intersubjetivos que develen lo humano que aparece en los rostros de los combatientes, las víctimas y los otros.

\section{Narrar el miedo}

El miedo es una emoción que activa la desconfianza tanto en la guerra como en la paz porque pone alertas ante la incertidumbre frente a los cercanos como a los lejanos; potencia la resistencia en el terreno de la guerra para mantenerse (Todorov, 2016). En la paz se manifiesta miedo (Nussbaum, 2019) frente al presente y el futuro, en un escenario que para ellos se percibe incontrolable, obligándolos a construir mecanismos para la defensa y la supervivencia. Por ello, estos excombatientes, al inicio del proceso de paz, tomaron con escepticismo el cumplimiento de los acuerdos por parte del Gobierno. Sin embargo, le apostaron a dicho proceso, aun sabiendo que sería difícil: "Salen de hacer la reunión y los matan, eso es muy triste para nosotros, pues, para el trabajo político como partido (...) pero así eso es tremendo, eso lo pone a pensar a uno. No hay garantías" (E3, M, 35; 211-215).

Ambos, enfrentando el miedo (Nussbaum, 2013), depositaron esperanza y amor en lo que les implicaba transitar a la vida civil, y cada uno empeñó todo por este proceso de paz. Una de las narradoras, desde su liderazgo y disposición para la reincorporación, plasmando acciones en pro de fortalecer el ETCR y no desistir ante la paz: "A uno le da miedo decir que fui guerrillera o soy (...) pero también uno en estos momentos siente muchas motivaciones" (E3, M, 35; 231-234). Y otro de los narradores, produciendo acciones con la comunidad campesina que habiliten acciones articuladas entre distintos actores para mostrar con todo el amor lo que las FARC hacían, y podían hacer, sin armas: "Que puedan conocer qué eran las FARC, pero sin armas, hay que impulsar esta paz” (E11, M, 40; 815-816).

Estos excombatientes reiteran querer la paz, pero quisieran tener garantías de protección, porque en la medida en que avanza el tiempo sienten que van exterminando líderes y excombatientes, y que muchos son como ellos, quieren otra oportunidad:

5 En la Vereda La Plancha Anorí, se ubica un punto transitorio de normalización en el que se concentró el frente 36 de las FARC - EP. Estos puntos transitorios fueron nombrados como Espacios Territoriales de Reincorporación y Capacitación, ETCR. 
El miedo es más temible cuando es difuso, disperso, poco claro; cuando flota libre, sin vínculos, sin anclas, sin hogar ni causa nítidos; cuando nos ronda sin ton, ni son; cuando la amenaza que deberíamos temer puede ser entrevista en todas partes, pero resulta imposible de ver en ningún lugar concreto. Miedo es el nombre que damos a nuestra incertidumbre: a nuestra ignorancia con respecto a la amenaza y a lo que hay que hacer. (Bauman, 2013, p. 10).

Para ellos, el miedo aparece también frente a la incertidumbre jurídica a la que están expuestos: "Nosotros no dejamos el monte para ir a una cárcel (...) se supone que lo dejamos porque vamos entonces a seguir la lucha políticamente" (E3, M, 35;250-252).

\section{A manera de conclusión}

Cabe resaltar la importancia que tiene una lectura del accionar bélico a la luz de las emociones políticas, ya que reflejan, desde sus atributos — como las creencias, juicios, valoraciones-, el lugar de posibilidad para leer los rostros en sujetos que han sido descalificados y estigmatizados. Las emociones son afecciones (Spinoza, 1975) de lo consciente que proporcionan comprender el mundo de la vida, el ser en el mundo y, en este caso, lo humano detrás de lo bélico. Las emociones van unidas a las creencias y, en este sentido, su contenido cultural permea el accionar político.

Por su carácter comunicativo, se forjan experiencias emocionales compartidas. Así, en un país tan polarizado como el nuestro, es fundamental ver la importancia que tiene una emoción como la vergüenza en elementos como la verdad, la justicia y la reparación, claves en un posacuerdo. Sin la vergüenza no habría un alto en el camino para poder reconocer y transformarse desde lo más profundo, que es el sentido ejemplarizante que concede dotar de nuevos sentidos la vida de los sujetos en reincorporación.

Es importante comprender también que los mismos móviles que activaron una emoción política, como la repugnancia ante la injusticia social, hoy se expresan en el deseo de no querer ver más sangre ni más armas en el caso de los narradores. Al igual que una emoción como el miedo que requiere de nuevos significados que consientan su elaboración y la transición a la no repetición. Finalmente, una emoción política como el amor, que estuvo presente al ingresar a la organización, permeando todo, y siendo el amor al pueblo y a la comunidad el más importante, hoy continúa con la misma intensidad, pero sin armas, porque hoy el anhelo es amar al pueblo a través de una lucha política que los reconozca.

Es fundamental, además, darnos una oportunidad para comprender estas narrativas que nos sitúan en el lugar de las diferencias en las que hemos vivido los colombianos, y en la obligación moral de comprometernos con el trabajo por la reconciliación, la paz y la construcción de otras vidas más dignas.

\section{Referencias}

Arendt, H. Los orígenes del totalitarismo. Madrid, España: Taurus, 1974.

Aristóteles. Ética Nicomáquea. Ética Eudemia. Madrid, España: Editorial Gredos, 1993.

Bauman, Z. Miedo líquido. La sociedad contemporánea y sus temores. Barcelona: Paidós, 2013. 
Castillejo, A. Los archivos del dolor: Ensayos sobre la violencia y el recuerdo en la Sudáfrica contemporánea. Bogotá: Uniandes, 2013.

Centro Nacional de Memoria Histórica. ¡Basta ya! Colombia: Memorias de guerra y dignidad. Bogotá: Imprenta Nacional, 2013.

CICR. La guerra y el derecho internacional humanitario. 2010. Recuperado de: https://www.icrc.org/es/doc/warand-law/overview-war-and-law.htm

Clausewitz, K. De la guerra. 2002. Recuperado de: https://lahaine.org/amauta/b2-img/Clausewitz\%20Karl\%20 von\%20-\%20De\%20la\%20guerra.pdf

Elías, N. El proceso de la civilización: Investigaciones socio genéticas y psicogenéticas. México: Fondo de Cultura Económica, 2012.

Estrada, J. El acuerdo de paz en Colombia. Entre la perfidia y la potencia transformadora. Bogotá: Cepdipo, 2019.

FARC-EP. Estatuto FARC- EP. 1966. Recuperado de: https://www.farc-ep.co/octava-conferencia/reglamento-deregimen-disciplinario-farc-ep.html

FARC-EP. “Resistencias". Revista internacional 37(2009). Recuperado de: https://issuu.com/martincaballero7/docs/ $\underline{\text { revres } 37}$

Gadamer, H. Verdad y método. Volumen I. Salamanca: Ediciones Sígueme, 1977.

Guzmán, G., Fals, O. y Umaña, L. La violencia en Colombia. Bogotá: Editorial La Carreta, 2014.

Heller, A. La teoría de los sentimientos morales. México: Ediciones Coyoacán, 2004.

Kant, I. Fundamentación de la metafísica de las costumbres. San Juan de Puerto Rico, Puerto Rico: Editorial Pedro M. Rosario Barbosa, 2007.

Levi, P. Trilogía de Auschwitz. Barcelona: Editorial Ariel, 2015.

Marín, M. "La repugnancia: una emoción política en el conflicto armado colombiano".

Revista de ciencias sociales y humanidades 4.7 (2018).

Marín, M y Quintero, M. “Emociones políticas y mal”. Revista Eleuthera 16 (2017): 101 - 117.

Nussbaum, M. Paisajes del pensamiento. La inteligencia de las emociones.

Barcelona, España: Editorial Paidós, 2008. .

Nussbaum, M. El ocultamiento de lo humano. Repugnancia, vergüenza y ley. Madrid:

España: Katz Editores, 2012.

Nussbaum, M. La nueva intolerancia religiosa. Cómo superar la política del miedo en una época de inseguridad. Barcelona: Paidós Estado y sociedad, 2013.

Nussbaum, M. Emociones políticas. ¿Por qué el amor es importante para la

justicia? Barcelona, España: Paidós Estado y Sociedad, 2014.

Nussbaum, M. Sin fines de lucro. Por qué la democracia necesita de las humanidades. Bogotá: Katz Editores, 2014.

Nussbaum, M. La monarquía del miedo. Una mirada filosófica a la crisis política actual. Barcelona, España: Paidós, estado y sociedad, 2019.

Polarización del país, reflejada en resultados del escrutinio. El Tiempo.

Octubre 2 de 2016. Recuperado de: https://www.eltiempo.com/politica/proceso-de-paz/resultadosplebiscito-2016-42861

Proceso de paz: Así comenzó todo. Revista Semana. Mayo 12 de 2020.. Recuperado de: https://www.semana.com/ nacion/articulo/proceso-de-paz-asi-comenzo-todo/440079-3

Quintero, M. Usos de las narrativas, epistemologías y metodologías: Aportes para la investigación. Mimeo, 2014.

Quintero, M. Usos de las narrativas, epistemologías y metodologías: Aportes para la investigación. Bogotá: Universidad Distrital Francisco José de Caldas, 2018.

"Presidente Duque levanta la mesa de diálogos de paz con el ELN". El Espectador. Enero 18 de 2019. Recuperado de: https://www.elespectador.com/noticias/politica/presidente-duque-levanta-la-mesa-de-dialogos-de-pazcon-el-eln-articulo-834823

"Proceso de paz: Así comenzó todo". Revista Semana. Mayo 12 de 2020. Recuperado de: https://www.semana.com/ nacion/articulo/proceso-de-paz-asi-comenzo-todo/440079-3

Rawls, J. Teoría de la justicia. México: Fondo de Cultura Económica, 1997.

Redacción El Tiempo 63 mil personas se han movilizado en Colombia. El Tiempo. Octubre 27 de 2016. Recuperado de: www.eltiempo.com/especiales/cifras-de-desmovilizados-en-colombia-49334

Ricoeur, P. "La vida: un relato en busca de un narrador". Revista Ágora. Papeles de filosofía 25. 2 (2006): 9 - 22. 
Ricoeur, P. “Narrative preconstruction”. Narrative Inquiry 16 (2006).

Ricoeur, P. Amor y justicia. México: Siglo XXI, 2009.

Safranski, R. El mal o el drama de la libertad. Barcelona: Tusquets Editores, 2000.

Spinoza, B. Ética. Buenos Aires: Editorial Aguilar, 1975.

Springer, N. Como corderos entre lobos. Del uso y reclutamiento de niñas, niños y adolescentes en el marco del conflicto armado y la criminalidad en Colombia. Bogotá: Naciones Unidas, 2012.

Taylor, Ch. Las fuentes del yo. La construcción de la identidad moderna. Barcelona: Paidós.

Todorov, T. Los abusos de la memoria. Barcelona: Paidós, 2000.

Todorov, T. El miedo a los bárbaros. Barcelona: Galaxia Gutenberg, 2016.

Uribe, A. Perfiles del mal en la historia de Colombia. Bogotá: Universidad Nacional, 2009. 